تمرينات خاصة لتطوير الأنظمة الهوائية واللاهوائية وأثرها في بعض المتغيّرات الوظيفية والقدرات البذنية للاعبي لفئة الثباب (17 - 9 (1) سنة بكرة القدم

م.د.محمد غني حسين

كلية التربية الأساسية/ الجامعة المستنصرية
أ.م. .د. علي فؤاد فائق

كلية التربية الأساسية/ الجامعة المستتصرية

ملخص

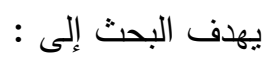

ا ـ اعداد تمرينات لنطوير القدرات الهوائية واللاهوائية تتلاعم وقدرات عينة البحث .

r. معرفة تأثثر تمرينات في بعض المتغيرات الوظيفية والقدرات البدنية للاعبي كرة القدم .

$$
\text { فرضيات البحث :- }
$$

1- توجد فروق ذوات دلالة إحصائية بين نتائج الاختبارات القبلية والبعدية لمجموعات البحث في بعض المتغيرات الوظيفية والقدرات البدنية للاعبي من عينة البحث ولصالح الاختبارات البعدية.

ץ- توجد فروق ذوات دلالة إحصائية بين نتائج الاختبارات البعدية لمجموعات البحث في بعض المتغيرات الوظيفية والقدرات البدنية للاعبي من عينة البحث ولصالح المجاميع التجريبية.تم استخدام المنهج التجريبي وتم اختيار عينة البحث من لاعبين نادي الصليخ لفئة الثباب ، وأسفرت النتائج هناك فروق معنوية بين الاختبارات البعدية لكلا المجموعتين البحث ولصالح المجموعة التجريبية في متغيرات المبحوثة قبد البحث مما يدل ذلك على فاعلية تمرينات المقترحة . 


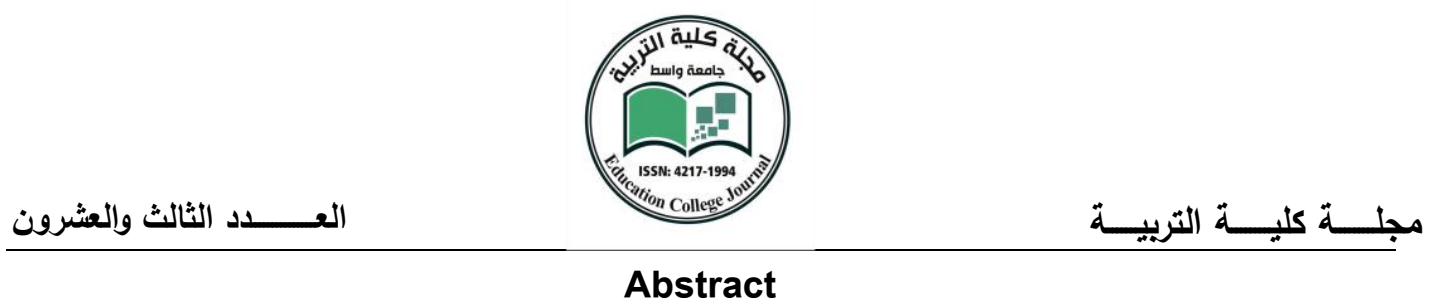

The research aims to:

.' Preparation exercises to develop the aerobic and anaerobic capacity and fit the capabilities of the research sample.

.rknow the effect of exercise in some functional variables and physical abilities of the football players.

\section{Research hypotheses- :}

-'There are statistically significant differences between the results of the tests and tribal posteriori the research groups in some functional variables and physical abilities of the players from the research sample and in favor of a posteriori tests.

-rThere are statistically significant differences between the results of the post tests of the research groups in some functional variables and physical abilities of the players from the research sample and in favor of aggregates Altjeribih.tm the use of the experimental method has been selected sample of players Suleikh club for young people, and resulted in the results there are significant differences between the post tests Search for both groups and in favor of the experimental group in the researched variables in question suggesting that the effectiveness of the proposed exercises. 


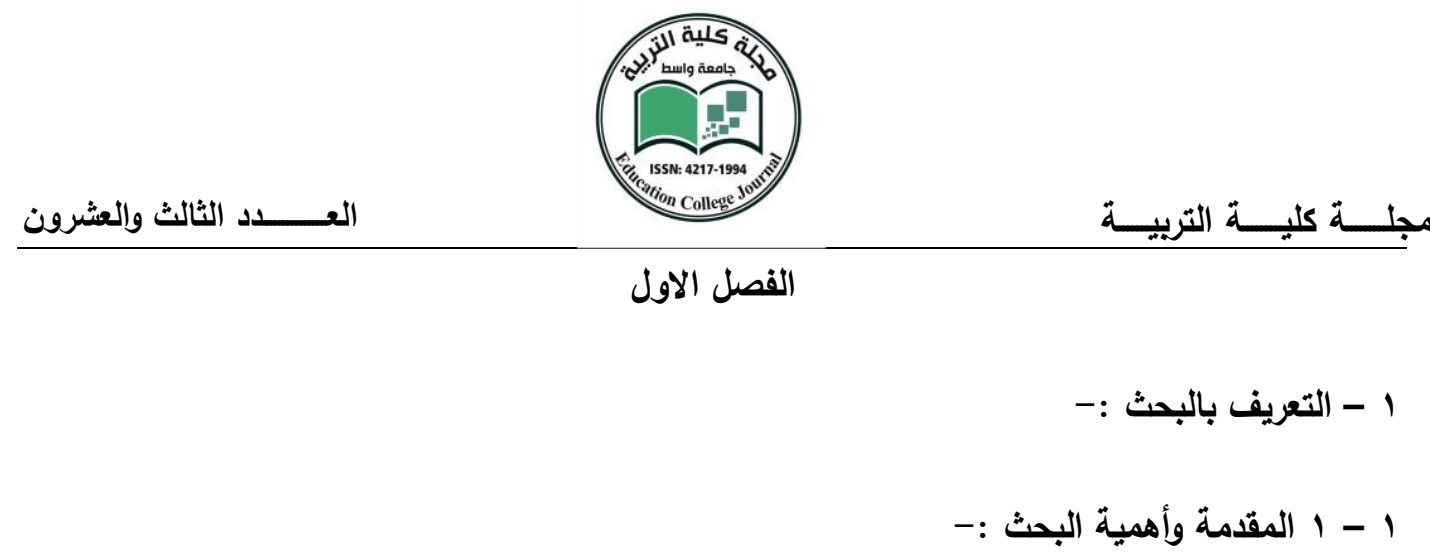

إن الأسس الواجب توافرها لنجاح عملية التدريب بشكل عام تتركز في وضع المناهج التدريبية المبنية على الأسس العلمية في جوانب الأعداد الثامل سواء المهاري او الخططي او النفسي ، الذي يتركز باستخدام أساليب تدريبية علمية صحيحة تتسجم والعنصر المراد تطويره سواءً أكان بدنياً أو مهاريا إذ على الى الددرب أن يكون فنانا في اختيار الأسلوب المناسب لثكل الرياضة التي يعمل فيها التي يمكن استخدامها من بقية الأساليب الأخرى لأجل تطوير أي عنصر من عناصر اللياقة البدنية والمهارات الاساسية بكرة القدم وتحسينها لغرض لتحقيق ما ينبغي تحقيقه التي نسهم في تطوير مستوى اللاعبين على وفق نظريات ومفاهيم التدريب الرياضي ونطبيقاته العملية .

وتحتل التغيرات التي تحصل في العضلات أثناء التدريب البدني أهية خاصة نظراً لارتباطها بإنتاج الطاقة على أن هناك نوعين من أنواع العمل هما العمل اللاهوائي والعمل الهوائي يعملان على وفق خصوصية الفعالية الرياضية ، وتعتمد بعض الأنشطة الرياضية على العمل اللاهوائي في الحصول على الطاقة اللازمة لها وتسمى بأنشطة العمل اللاهوائي بينما تعتمد بعض الأنشطة الرياضية الأخرى على العمل الهوائي في الحصول على الطاقة اللازمة لهما أي على كفاءة الجهاز الدوري والتتفسي وتنمى العمل الهوائي .

تُعُدُ لعبة كرة القدم أسرع لعبة من بين ألعاب الجماعية الأخرى وتوصف بأَّها لعبة مهارية تكتيكية بالدرجة الأولى وعند التمعن في طبيعة الأداء الذي يتميز بأنه بحتاج إلى أنتاج الطاقة لأداء الأعمال العضلية السريعة والقوية اعتمادا على الإنتاج اللاهوائي للطاقة وعلى الرغم من سيطرة النظام اللاهوائي على مفردات العمل في لعبة كرة القدم • 
العــــــد الثالث والعشرون

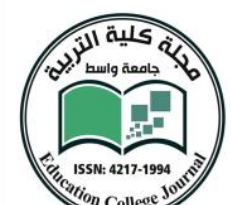

إلا أن مدة المباراة وعدم تحديدها بوقت معين يجعل من الضروري الأخذ بنظر الاعنبار أهمية النظام الهوائي الذي يوفر من الطاقة ما يحتاجه العمل التحملي خلال مدة المباراة كاملة. مما تقدم نلاحظ أن لعبة كرة القدم في كل منطلباتها هي عبارة عن خليط من الحاجة إلى القدرات الهوائية واللاهوائية.

وتكمن أهمية البحث في إعداد تمرينات بالاعتماد على استخدام أنظمة الطاقة خلال تقنين مفرداته بصورة علمية تتلاءم مع منطلبات اللعبة لتطوير بعض المتغيرات البدنية والفسيولوجية لفئة مهمة من اللاعبين ألا وهي فئة الثباب ليتم بناؤهم التدريبي بشكل علمي ليتسنى لنا نطويرهم مستقبلا ليكونوا ناجحين في تمثيل البلد مستقبلا ضمن المنتخبات الوطنية .

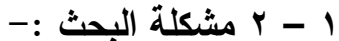

ومن خلال الملاحظة الثخصية للباحثن على عدد من المباريات التي أقيمت في الدوري العراقي بكرة القدم وجد الباحثان أن هناك ضعفاً واضحاً في المتطلبات البدنية والوظيفية الخاصة بلاعبي كرة القدم ، إذ تُعُد لعبة كرة القدم من الألعاب التي تتميز ببذل الجهذ كبير من قبل اللاعبين اثثاء سبر المباراة ، وقد ارتأى الباحثان استخدام التمرينات نظامين اللاهوائي والهوائي في رفع مستوى كفاءة الاجهزة الداخلية وقدرات البدنية للاعب لامكان الارتقاء بالمستوى اللعبة في قطرنا الحبيبب .

$$
\begin{aligned}
& 1 \text { - r أهداف البحث :- } \\
& \text { يهدف البحث إلى : }
\end{aligned}
$$

1. إعداد تمرينات خاصة لنطوير القدرات الهوائية واللاهوائية تتلاعم وقدرات عينة البحث .

r. معرفة تأثثر تمرينات خاصة في بعض المتغيرات الوظيفية والقدرات البدنية للاعبي كرة القدم • 
1- توجد فروق ذوات دلالة إحصائية بين نتائج الاختبارات القبلية والبعدية لمجموعات البحث في بعض المتغيرات الوظيفية والقدرات البدنية للاعبي من عينة البحث ولصالح الاختبارات البعدية.

ץ- توجد فروق ذوات دلالة إحصائية بين نتائج الاختبارات البعدية لمجموعات البحث في بعض المتغيرات الوظيفية والقدرات البدنية للاعبي من عينة البحث ولصالح الهجاميع التجريبية.

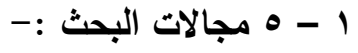

1- 0-1 المجال البشري : شباب نادي الصليخ بأعمار (17 (19 1) سنة .

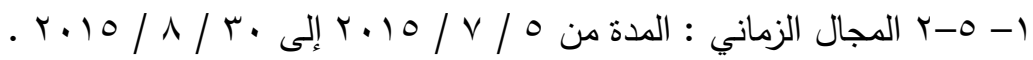

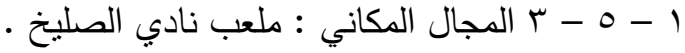




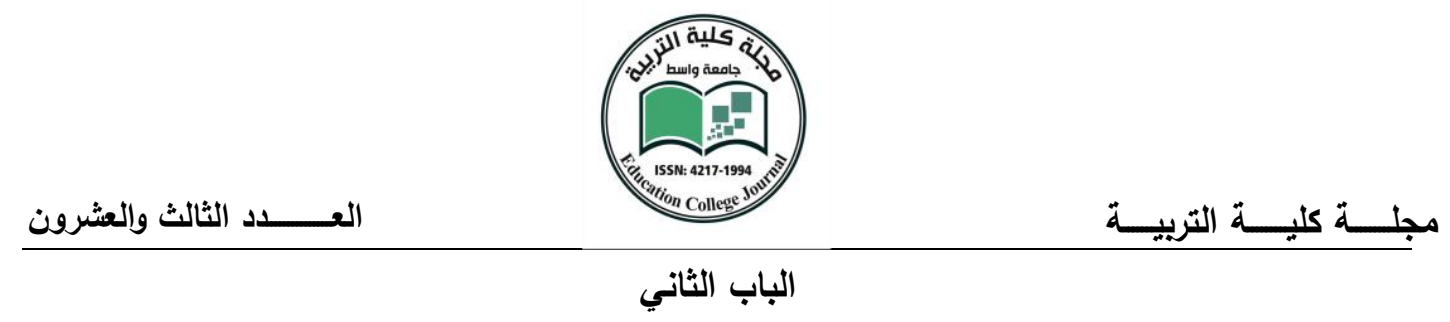

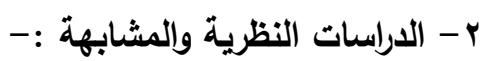

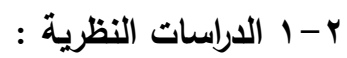

\section{': Anaerobic System -1-1 النظام اللاهوائي}

يُعُّد هذا النظام أساسياً في تدريب الفعاليات الرياضية التي تعتمد على إنتاج الطاقة اللاهوائية فهو بذلك ضروري لتدريبات السرعة. بعتمد هذا النظام على ثلاثي فوسفات الادنوسين “ " ATP والفوسفو كرياتين"CP " بدون تدخل يذكر للأوكسجين" •إن كمية "ATP" الموجودة في العضلة وحتى في عضلات الرياضيين المدربين جيداً لا تكفي لإدامة القدرة العضلية القصوى أكثر من ثلاثة ثوان بينما هناك الكثير من الأنشطة الرياضية تعتمد بالدرجة الأساس على المطاولة اللاهوائية كسباقات العدو السريع لذلك من الضروري أن ينولد “ ATP " جديدا باستمرار ويبدأ تحرير الطاقة بعد نفاذ مخزون “ ATP " من العضلة CP"CP" CP ". وهو مركب كيميائي آخر ذو رابطة فوسفاتية عالية الطاقة يسنطيع الفوسفو كرياتين " من تجهيز كمية كافية من الطاقة لإنتاج “ ATP " سواء مباشرة أو عن طريق اتحاد أيونات الفوسفات المتحللة من "CP " مع "ADP " أو "AMP" ، فضلا عن أن وجود " CP " في العضلات أكثر بضعفين إلى أربعة أضعاف كمية “ATP ”. والأهم من ذلك إن الطاقة المخزونة في الفوسفو كرياتين العضلة تكون مستُُّدة بصورة فورية للتقلص العضلي وتتم خلال جزء صغير من الثانية وتُسمى الكميات المتحدة من ATP CP " ، ، الخلايا بنظام الفوسفاجين للطاقة الذي يولا قدرة عضلية ومطاولة لاهوائية تمند إلى حدود (• (نانية) وهي كافية تقريبا لإنهاء ركض . . . متر بأقصى سرعة 


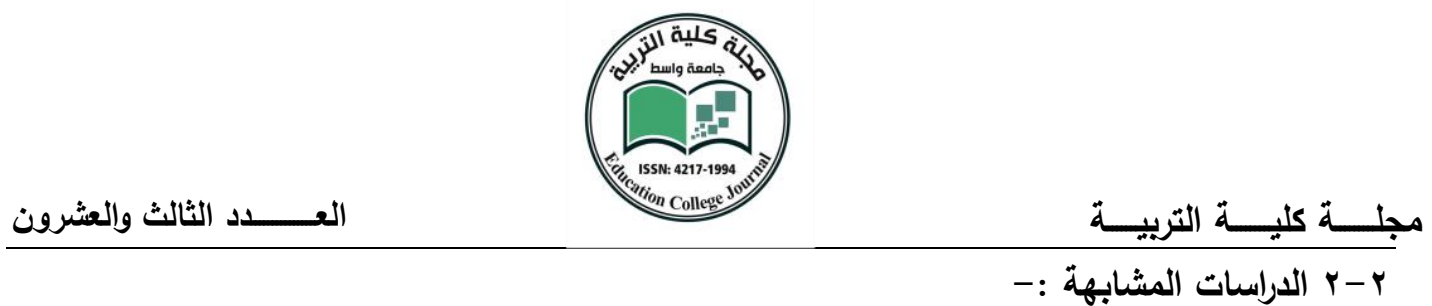

r-r-1 دراسة إيمان نجم الدين عباس ((منهج تدريبي مقترح لتطوير القدرة اللاهوائية والهوائية وتأثيرها في

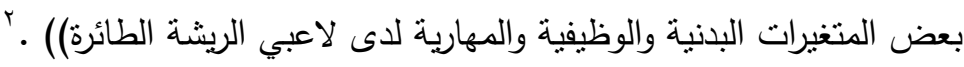

هدفت الدراسة إلى :

1. وضع مفردات منهج تدريبي مقترح لنطوير القدرة الهوائية واللاهوائية للناششين بالريشة الطائرة بأعمار

$$
\text { . }
$$

r. معرفة نأثير المنهج التدريبي المقترح في بعض المتغيرات البدنية والوظيفية والمهارية بالريشة الطائرة

$$
\begin{aligned}
& \text { بأعمار (ع ا- 17 1) سنة . } \\
& \text { فرضات البحث :- }
\end{aligned}
$$

ا ـ توجد فروق ذوات دلالة معنوية بين الاختبارين القبلي والبعدي للجموعتين التجريبية و الضابطة ولصالح الاختبارات البعدية في بعض القدرات البدنية والفسيولوجية والمهارية الخاصة بلاعبي الريشة الطائرة

r. توجد فروق ذوات دلالة معنوية في الاختبارات البعدية للمجموعتين التجريبية والضابطة ولصالح المجموعة التجريبية في بعض القدرات البدنية والفسيولوجية والمهارية الخاصة بلاعبي الريشة الطائرة . -

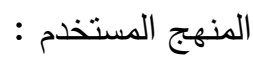

استخدم الباحث المنهج التجريبي اما عينة الدراسة فاشتملت على (··) ناشئي نادي المحاويل الرياضي بالريشة الطائرة ، نم تقسيم العينة إلى مجموعتين متكافئتين إحداهما تجريبية والأخرى ضابطة

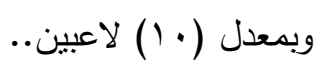




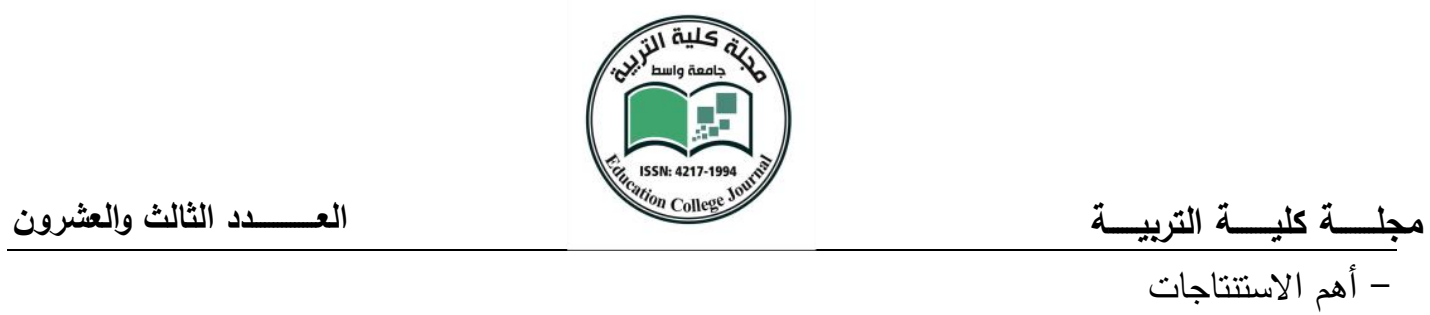

- حقق أفراد المجموعة التجريبية نسبة نطور أعلى بمستوى نطور في الصفات البدنية والمتغيرات الوظيفية قياسا بأفراد المجموعة الضابطة الذين حصلوا على نسبة تطور أقل . 


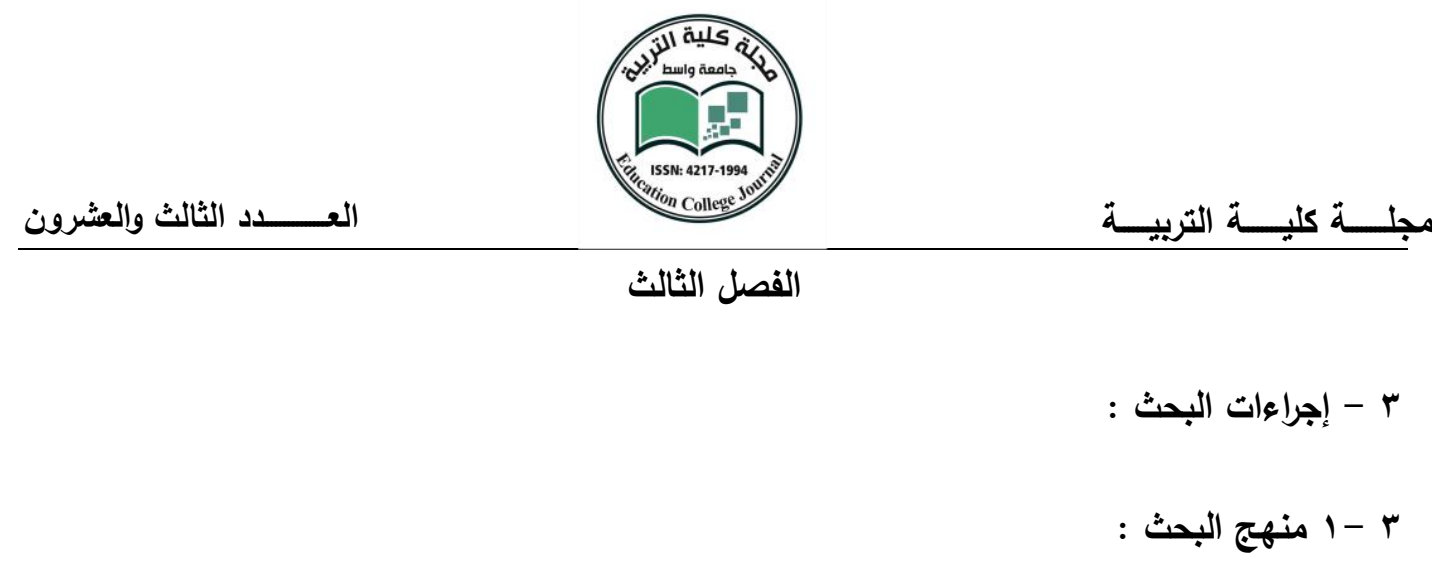

يعد المنهج التجريبي من أدق أنواع المناهج وأكثرها كفاية في التوصل الى نتائج دقيقة موثوق بها ، لذا استخدم الباحثان ان المنهج التجريبي لأنه اكثر المناهج ملاعمة لحلّ مشكلة بحثها إذ إنّ ((المنهج التجريبي يمثل طريقة منميزة حيث يمكن فهيا على افضل وجه من خلال الموازنة ومن خلال البرهنة على وجود علاقة سبيية تتضمن الموازنة بين الجماعات)) ، ، استخدم الباحثان المنهج التجريبي لملائمة وطبيعة

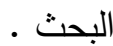

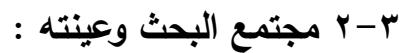

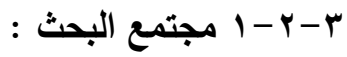

حدد الباحثان المجتمع بلاعبي أندية بغداد لفئة الثباب (7 ا- 9 (1) سنة والبالغ عددهم (^) إذ كان عددهم (^) (Y) ، وقد تم اختيار مجتمع البحث بالطريقة العمدية والمتمثل بفرق الدوري الممتاز بكرة القدم

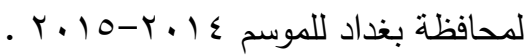

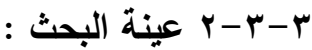

قام الباحثان باختيار العيّنة بالطريقة العشوائية إذ (( تتيح للباحث التعمق في إصدار الإحكام واتخاذ القرارات ويتم التصميم فيها عن طريق الاستدلال الإحصائي)) ؛ ، التي تمنل مجتمع البحث الأصلي المتمثل بلاعبي شباب نادي الصليخ بكرة القدم والبالغ عددهم (^^) لاعبا ، وبواقع (ع () لاعباً لكل 
العـــــدد الثالث وإلعشرون

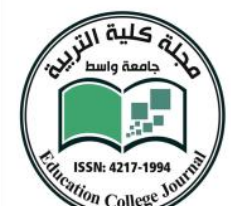

مجموعة عن طريق القرعة وطبقت التمرينات المقترحة على المجموعة التجريبية اما المجموعة الثانبة (الضابطة) قد طبقت الأسلوب المتبع لهم من قبل الدرب دون تدخل.

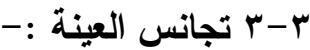

من أجل حصول على تجانس بين أفراد عينة البحث ولمنع المؤثرات التي قد تؤثر على نتائج التجربة من حيث الفروق الفردية الموجدة لدى اللاعبين في العمر والعمر التدريبي والقياسات الطول والوزن قام الباحثان بإيجاد معامل الالنواء للمتغيرات الاربعة ، وقد دلت على ان جميع القياسات تحقق المنحى الاعتدالي والذي

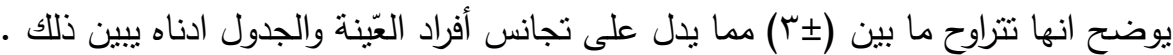

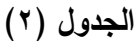

يبين تجانس العينة في القياسات الانثرويومترية

\begin{tabular}{|c|c|c|c|c|c|c|}
\hline معامل الالتواء & الانحراف & الوسيط & الوسط الحسابي & وحدة & المتغيرات & $ت$ \\
\hline ., IV. & 0,01 & $18 \% .91$ & $17 \Lambda, \leqslant r$ & سم & الطول & 1 \\
\hline .,940 & $0 . .4$ & 78.91 & $M Y, V Y$ & كفم & الوزن & $r$ \\
\hline$\therefore .9 v$ & r.r. & IV... & IV.T & سنة & العمر & $r$ \\
\hline. .19 & $1 . \pi r$ & $\varepsilon$ & ؛ & سنة & العمر التدريبي & $\varepsilon$ \\
\hline
\end{tabular}




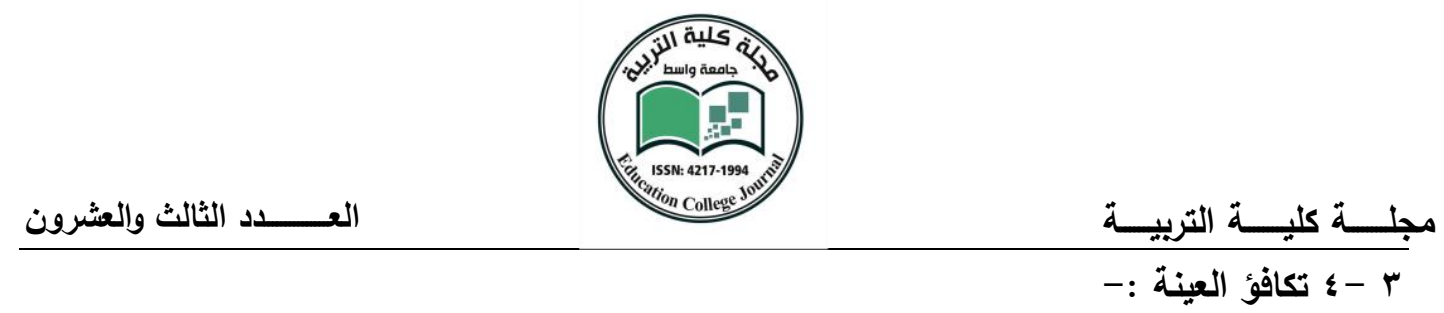

عمد الباحثان بتقسيم عينة البحث إلى مجموعتين باعتماد الطريقة العشوائية (القرعة) ولكي يكون تقسيم المجاميع غير منحاز لمجموعة ما ، ومن اجل الحفاظ على الموضوعية العلمية ، اجريت عملية التكافؤ في الاختبارات البدنية والوظيفية لمجموعتي البحث لضبط المتغيرات باستخدام قانون (T) للعينات المترابطة ، اذ وجد قيمة (t) المحسوبة أصغر من قيمة الجدولية مما يدل على عدم وجود فروق ذوات دلالة إحصائية بين المجموعتين وهذا يدل على تكافؤ العينة كما يدل على ان خط الشروع واحد كما مبين في

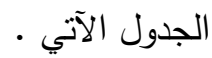

\section{جدول (r)}

" يبين تكافؤ العينة في الاختبارات القبلية للمجموعتين الضابط والتجريبية "

\begin{tabular}{|c|c|c|c|c|c|c|c|c|}
\hline \multirow[t]{2}{*}{ د دلالة } & \multirow{2}{*}{ قالمتسبة T } & \multicolumn{2}{|c|}{ التجريبية } & \multicolumn{2}{|c|}{ الضابطة } & \multirow[t]{2}{*}{ وحدة القياس } & \multirow{2}{*}{ المتغيرات } & \multirow[t]{2}{*}{ ت } \\
\hline & & $\varepsilon \pm$ & سَ سَ & $\varepsilon \pm$ & سَ س & & & \\
\hline غعنوي & 1.07 & $1 . . \varepsilon$ & $\{.71$ & $1.1 \pi$ & $\varepsilon, 09$ & ثا & السرعة الانتقالية & 1 \\
\hline غنوير & $1 . .7$ & A..r & דצ.rT & $V .9 Y$ & $7 r .07$ & منز/ثانية & اختبار الخطوة لمدة & r \\
\hline غنوير & $1 . \wedge \mathrm{V}$ & $1 . \varepsilon \varepsilon$ & $1 \wedge . \leqslant \Gamma$ & $1 . r o$ & $1 \wedge . T^{\prime}$ & منر/دقيقة & $\begin{array}{c}\text { الأكسجينية مؤشر القابلية } \\
\text { Vo2Max } \\
\text { النسبية }\end{array}$ & r \\
\hline غعنوير & $1.1 \leqslant$ & 17.Ar & $v q \leq .1 . r$ & $10 . r \leq$ & $\vee \wedge 9.77$ & سمץ & حجم القلب المطلق & $\varepsilon$ \\
\hline غنوير &. .99 & r.7o & Ir.Ar & T.VT & $1 T .07$ & سمץ//كغم & حجم القلب النسبي & 0 \\
\hline غعنوي & 1.rT & $9 r . \leq r$ & $0 . \leqslant 0.1$ & VA.T & $0 . r 4 . r$ & مللتر/بالاقيقة & الناتج القلبي & 7 \\
\hline
\end{tabular}




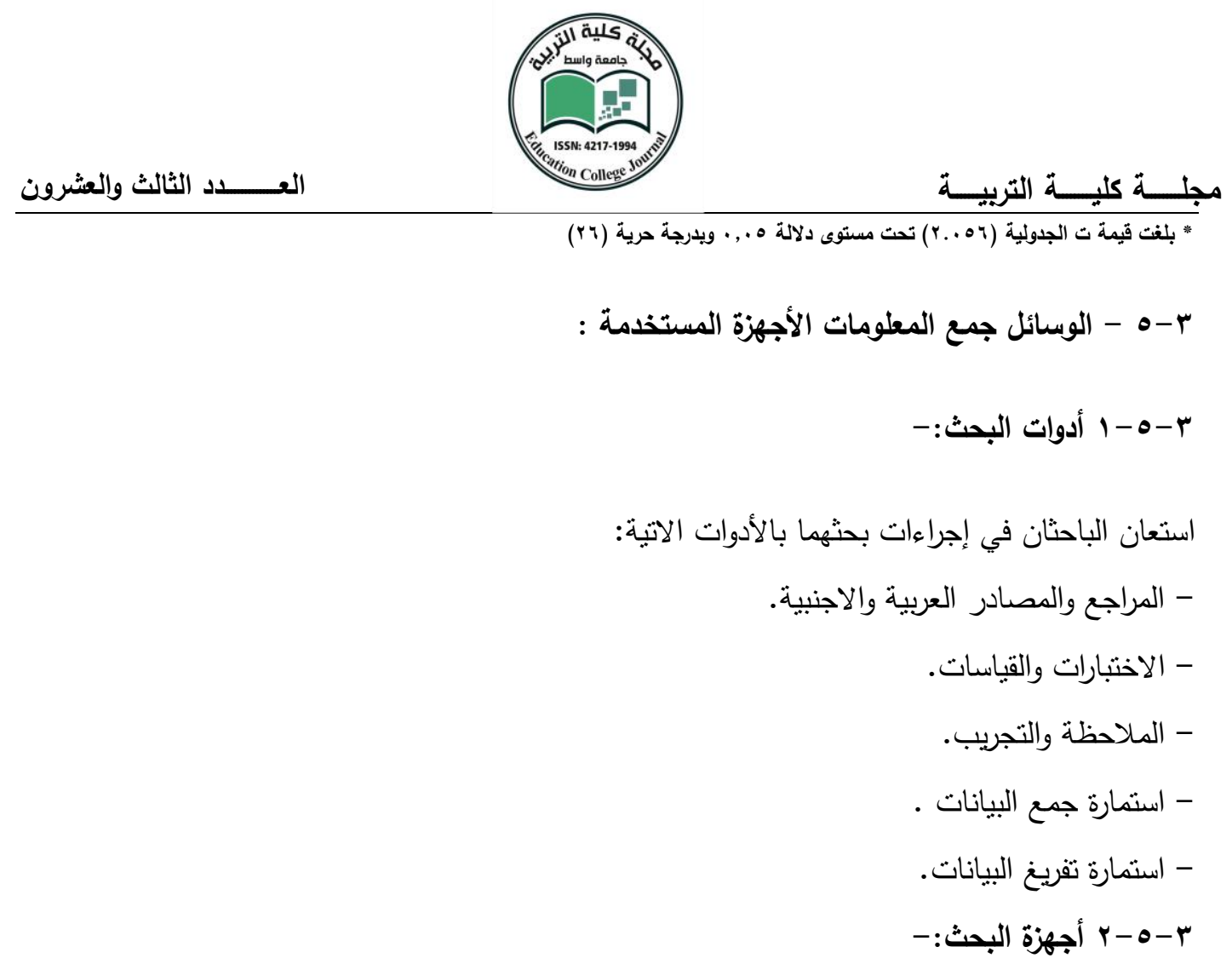

استعان الباحثان في اجراءات بحثهما بالأجهزة الآتية:

- جهاز طبي قياس الطول والوزن • - ساعة توقيت الكترونية يدوية (الماني الصنع).

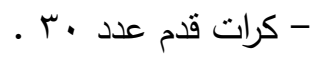
- شواخص بلاستيكية عدد (Yo).

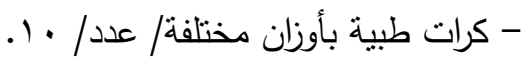

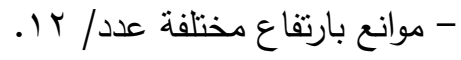
- لوحات حديدية ددرجة بالسنتمتر بارتفاع (זم) لقياس الطول .

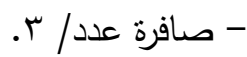
- شريط قياس معدني بطول (•0م) عدد (1) مع حبال عدد (乏) بطول (0) م . 登... 


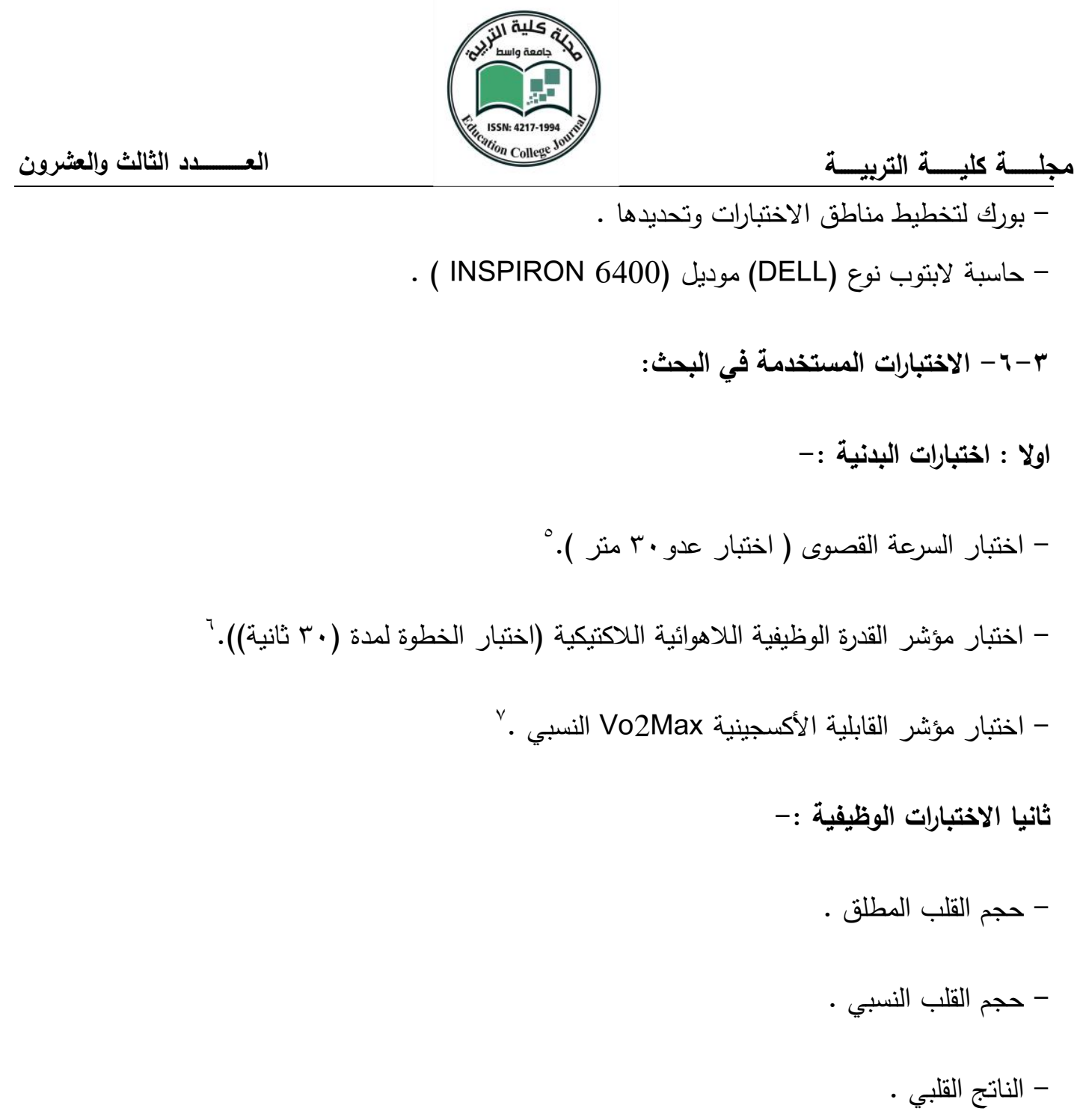

إنَ الاختبارات التي أجراها الباحتان كانت على نوعين وهي اختبارات وظيفية واختبارات بدنية ، وبما أن تتفيذ بعض الاختبارات الوظيفية ينطلب نوافر أجهزة ومعدات طبية على درجة عالية من الدقة كجهاز الايكو مثناً ، مما دعا الباحثين إلى القيام بنقل عينة البحث إلى مستشفى نعمان في الأعظمية للقلب والأوعية الدموية وذلك لكون أن هذه المستشفى تتميز بتوفر أجهزة حديثة ومعدات طبية منطورة في هذا المجال ، وبالنظر لصعوبة إجراء الاختبارات الوظيفية لعينة البحث دفعة واحدة ، وذلك بسبب الزخم الكبير من المرضى والمراجعين إلى هذه المستشفى (النعمان) ، مما أدى الباحثان إلى تقسيم عينة البحث المتكونة

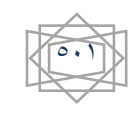


العـــــــدد الثالث والعشرون

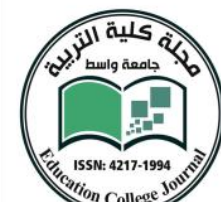

من (Y^) لاعباً إلى (V) مجاميع ، وكل مجموعة تتكون من (ع) لاعبين ، وتم تحديد لكل مجموعة يوم

لإجراء الاختبارات الوظيفية وبذلك تم إجراء الاختبارات بانسيابية وبالدقة المطلوبة وبدون تلكؤ .

ومن جهة أخرى فقد حرص الباحثان على إجراء الاختبارات البدنية بصورة منزامنة مع الاختبارات الوظيفية ، أي أن المجموعة التي يجري لها الاختبارات الوظيفية الساعة (• ( ) صباحاً يتم إجراء الاختبارات البدنية لها الساعة (ع) عصراً من اليوم نفسه واليوم الذي يليه وذلك من أجل أن تكون نتائج البحث متسمة بالموضوعية والدقة العلمية فقد تم إجراءها في ملعب نادي الصليخ .

\section{: التجربة الاستطلاعية}

من أجل ضبط منغيرات الدراسة والوقوف على معوقات العمل والتأكد من التمرينات النوعية لتطوير متغيرات قيد الدراسة ، أجرى الباحثان تجربة استطلاعية قبل التجربة الرئيسة للبحث ، وذلك في يوم السبت

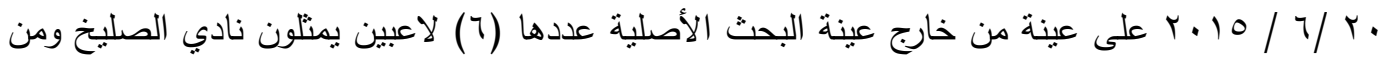
الذين لم يشتركوا في التجربة الأساسية ـ وكان الهدف من أجراء هذه التجربة الاتي :-

1- معرفة مدى ملائمة الاختبارات لعينة البحث. r- معرفة الوقت المستغرق لأداء الاختبارات. ب- معرفة مدى ملائمة الأدوات المستعملة. ع - معرفة المعوقات التي قد نواجه مجريات البحث. ه - إيجاد المعاملات العلمية للاختبارات . ب-N - المعاملات العلمية للاختبارات :

س-1-1- ثبات الاختبارات :- ((إن مفهوم الثبات هو (درجة الثقة) أي نتيجة الاختبار ( ذا قيمة ثابتة) خلال التكرار أو الإعادة ، أي بمعنى الثبات للنتائج التي حصل عليها الباحث إذا ما أعيدت التجربة على 
العــــــد الثالث وإلعشرون

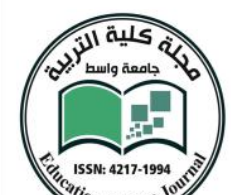

نفس المجموعات المشابهة )(^، وعلى هذا الأساس قام الباحثان بتطبيق الاختبارات ومن ثم أعادة تطبيقها على أفراد عينة البحث الاسنطلاعية بفارق زمني (0) أيام .

ץ-^-ץ- صدق الاختبارات :- (( تُعُّد درجة الصدق العامل الأكثر أهمية بالنسبة إلى محكات وجود الاختبار والمقاييس )) 9 . فقد استخدم الباحثان معامل الصدق الذواتي لجميع الاختبارات عن طريق

استخراج الجذر التربيعي لمعامل الثبات ويعني صدق الاختبار ـ كما مبين في جدول (r)

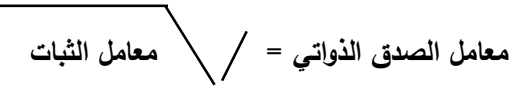

جدول (ז)

يوضح ثبات الاختبارات قيد الداسة

\begin{tabular}{|c|c|c|c|}
\hline الصدق الذواتي & الثبات & الاختبارات & 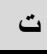 \\
\hline$. .9 \leqslant$ &..$\wedge 1$ & اختبار السرعة الانتقالية & 1 \\
\hline. .90 &. .9 . & اختبار الخطوة لمدة (·r ثانية) & r \\
\hline. .90 &. .91 & مؤشر القابلية الأكسجينية Vo2Max النسبي & r \\
\hline
\end{tabular}




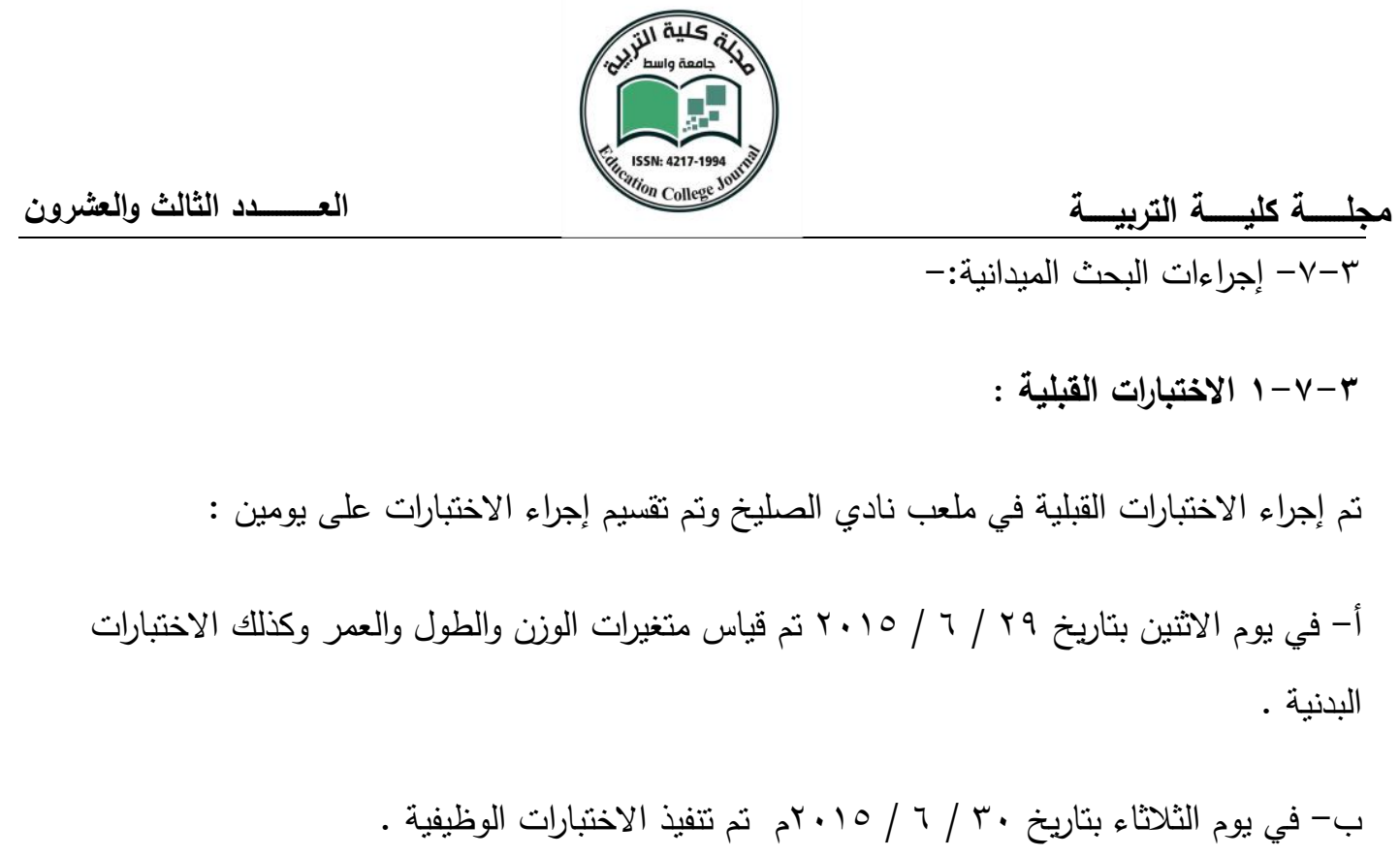

r- r- إعداد التمرينات التدريبية (لتطوير الأنظمة الهوائية واللاهوائية): ملحق (1)

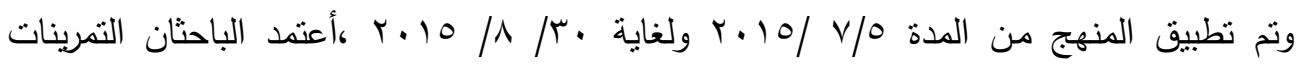
التدريبية المعدة من قبلهما وكانت التجربة الرئيسية لمدة (^) أسابيع إذ ذكر أبو العلا إلى أن ((معظم التغيرات الناتجة عن التدريب تحدث عادة خلال المدة الأولى من البرنامج في غضون (†-^) اسبوع ))' ، وضمن فنرة الاعداد الخاص .

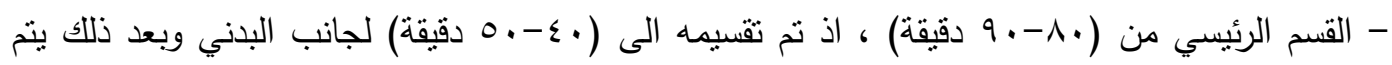
جمع اللاعبين مرة اخرى للاستكمال باقي الجزء الرئيسي من تمرينات المهارية والخططية . - نفذت التمرينات بواقع (r) وحدات تدريية اسبوعية واستخدام الباحث طريقة التدريب الفتري منخفض الثدة ومرتفع الثدة ، وهذا يعني أن مجموعتي البحث قد أخذت نفس الفترة الزمنية ولكن طبقت بأساليب مختلفة ، ومن أجل تحقيق نفس الظروف في الوحدات التدريبية وبالتالي السيطرة على متغيرات البحث ، فأن أفراد المجوعتين كانوا يتدربون كل مجموعة على حده المجموعة الأولى تتفذ التمرينات المعدة من فبل الباحثن والمجموعة الثانية (الضابطة) بالأسلوب المنبع من قبل مدرب الفريق . 


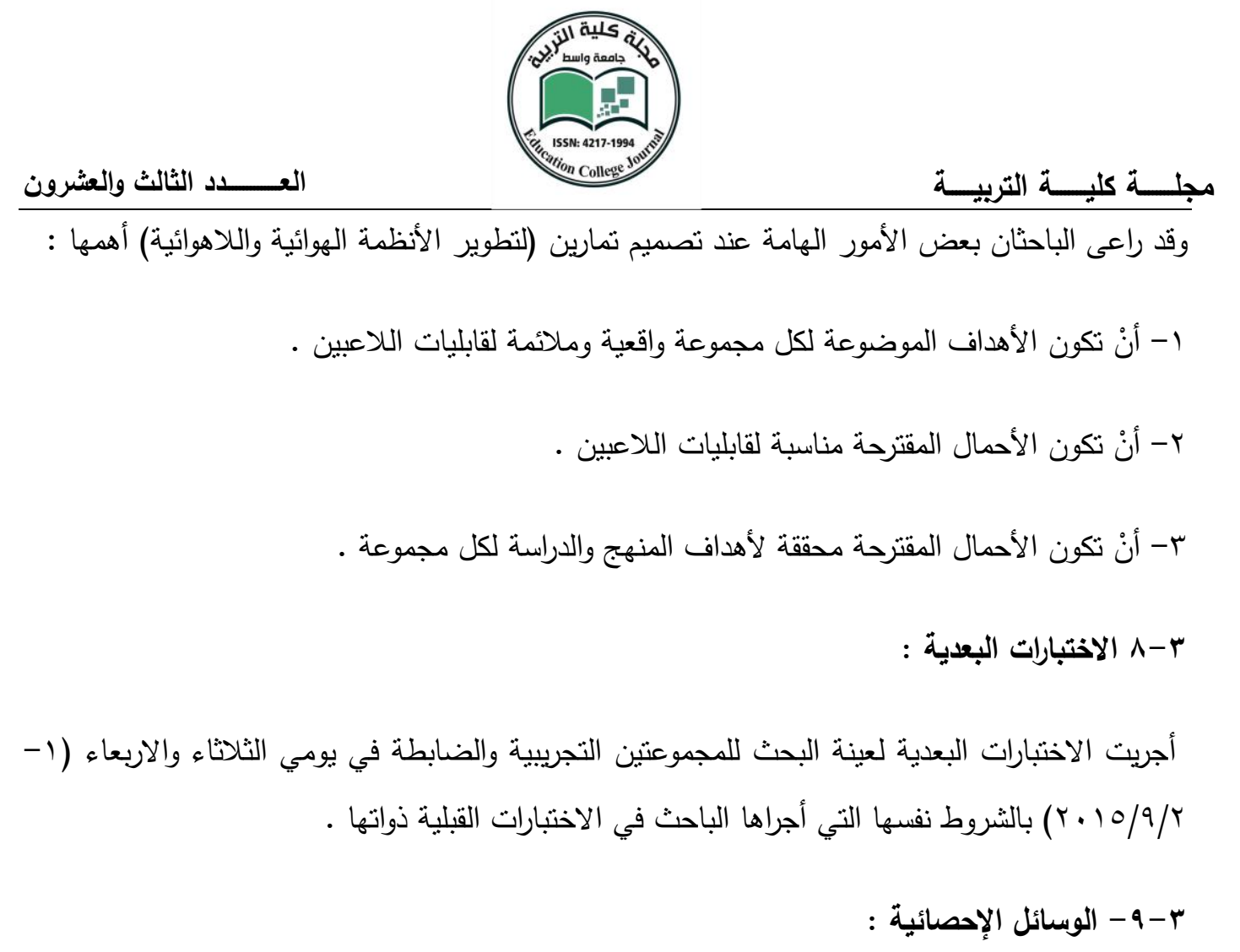

استخدم الباحثان الحقيبة الإحصائية ( spss )على جهاز الحاسوب لمعالجة كافة بيانات البحث للقوانين الإحصائية التالية : - الوسط الحسابي -

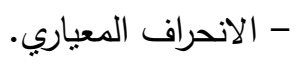
- معامل الارتباط البسيط (بيرسون). - اختبار (ت) للأوساط الحسابية الغير مرتبطة . - اختبار (ت) للأوساط الحسابية المرتبطة . 


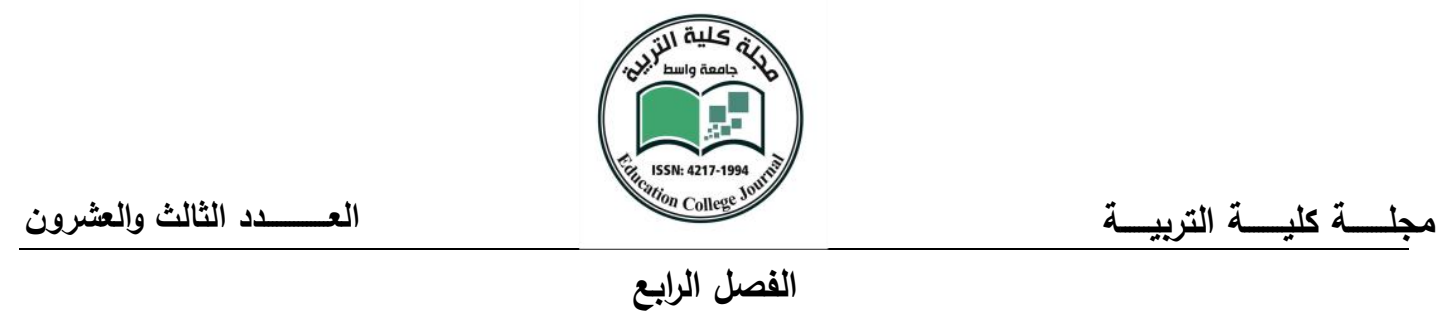

؛ - عرض النتائج وتحليلها ومناقثتها :

؛ - 1 - عرض وتحليل النتائج :

الجدول (ء) يبين المتوسط الحسابي والانحراف المعياري وقيم (ت) ودلالتها بين القياسين القبلي والبعدي لمتغيرات الدراسة للمجموعة الضابطة .

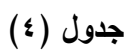

معنوية الفروق بين الاختبار القبلي والبعدي للمجموعة الضابطة

\begin{tabular}{|c|c|c|c|c|c|c|c|c|}
\hline \multirow[t]{2}{*}{ دلالة } & \multirow{2}{*}{ قالمحتسبة } & \multicolumn{2}{|c|}{ البعدي } & \multicolumn{2}{|c|}{ القبلي } & \multirow[t]{2}{*}{ وحدة القياس } & \multirow[t]{2}{*}{ المتغيرات } & \multirow[t]{2}{*}{ ت } \\
\hline & & $\varepsilon \pm$ & 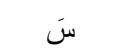 & $\varepsilon \pm$ & 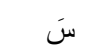 & & & \\
\hline معنوي & r... & r.1r & $\{. .1$ & $1.1 \%$ & $\varepsilon, 09$ & ثا & السرعة الانتقالية & 1 \\
\hline معنوي & r.Aт & r.乏^ & $70.1 \varepsilon$ & V.qY & $7 r .04$ & متر/ثانية & اختبار الخطوة لمدة & $r$ \\
\hline معنوي & $\varepsilon . .1$ & r.AI & $r . . r \varepsilon$ & 1.50 & 111.47 & متر/دقيقة & $\begin{array}{c}\text { الأكسجينية مؤشر القابلية النسبية } \\
\text { Vo2Max }\end{array}$ & $r$ \\
\hline معنوي & $r .01$ & IV.TN & 1.0 .01 & $10 . \Gamma \varepsilon$ & $\vee \wedge 9.74$ & سمץ & حجم القلب الدطلق & $\varepsilon$ \\
\hline معنوي & $0 . \leqslant 0$ & r..rY & $1 T . \wedge \varepsilon$ & r.VT & $1 Y .07$ & سم ץ//كغ & حجم القلب النسبي & 0 \\
\hline معنوي & T.I $\varepsilon$ & $T \varepsilon .9 T$ & $01 \leqslant \varepsilon . V$ & VA.T $\varepsilon$ & $0.44 . \mathrm{T}$ & مللتر/بالدقيقة & الناتج القلبي & 7 \\
\hline
\end{tabular}

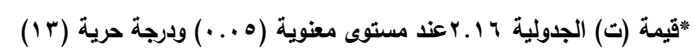

الجدول (0) يبين المتوسط الحسابي والانحراف المعياري وقيم (ت) ودلالتها بين القياسين القبلي والبعدي لمتغيرات الدراسة للمجموعة التجريبية . 


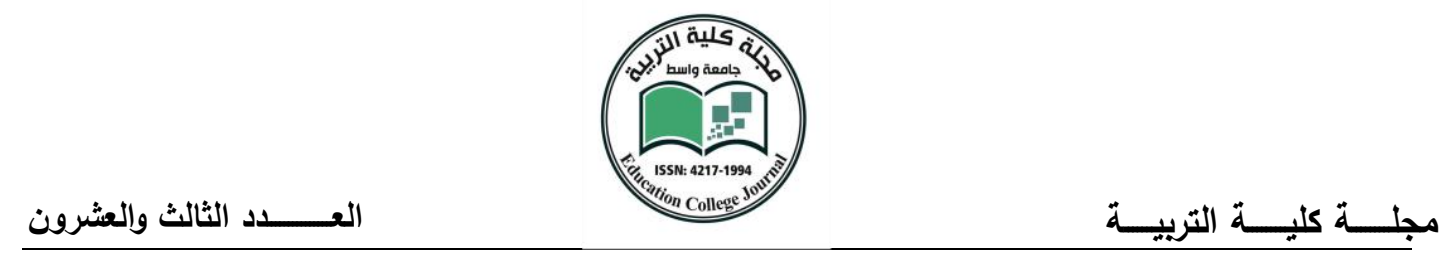

(•) جدول

معنوية الفروق بين الاختبار القبلي والبعدي للمجموعة التجريبية

\begin{tabular}{|c|c|c|c|c|c|c|c|c|}
\hline دلالة & قيمة T & \multicolumn{2}{|c|}{ البعدي } & \multicolumn{2}{|c|}{ القبلى } & وحدة القياس & المتغيرات & $ت$ \\
\hline & & $\varepsilon \pm$ & سَ س & $\varepsilon \pm$ & سَ سَ & & & \\
\hline معنوي & $7 . \wedge 7$ & $1.0 r$ & r.V & $1 . . \varepsilon$ & $\{.71$ & ثا & السرعة الانتقالية & 1 \\
\hline معنوي & A.Y人 & 9.71 & $\uparrow \wedge . \leqslant 0$ & A.. T & TT.YT & متر/ثانية & اختبار الخطوة لمدة & r \\
\hline معنوي & 1.90 & T.人T & Yr.ON & $1 . \leqslant \varepsilon$ & $1 \wedge . \leqslant \Gamma$ & متر/دقيقة & $\begin{array}{c}\text { الأكسجينية مؤشر القابلية } \\
\text { Vo2Max } \\
\text { النسبية }\end{array}$ & r \\
\hline معنوي & $9 . \wedge 1$ & IV.AT & $\wedge \leq 7.7 \wedge$ & 17.人 & $\vee q \leq .1 \cdot r$ & سمץ & حجم القلب المطلق & $\varepsilon$ \\
\hline معنوي & $11 . . r$ & 1.10 & $10.7 r$ & $r .70$ & Ir.Ar & سمץ//كغم & حجم القلب النسبي & 0 \\
\hline معنوي & $10 . . \times 7$ & Аะ.7T & $7.97 \leq .0$ & 9 q५. & $0 . \leqslant 0.1$ & مللتر/بالدقيقة & الناتج القلبي & 7 \\
\hline
\end{tabular}

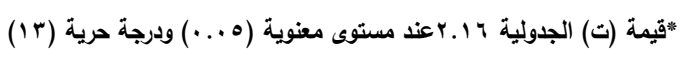

وبعد إن فرغ الباحثنان من اختبارات البعدية للمجموعتين البحث عمدا إلى تفريغ البيانات ومعالجتها

• إحصائيا كما في الجدول (T) 


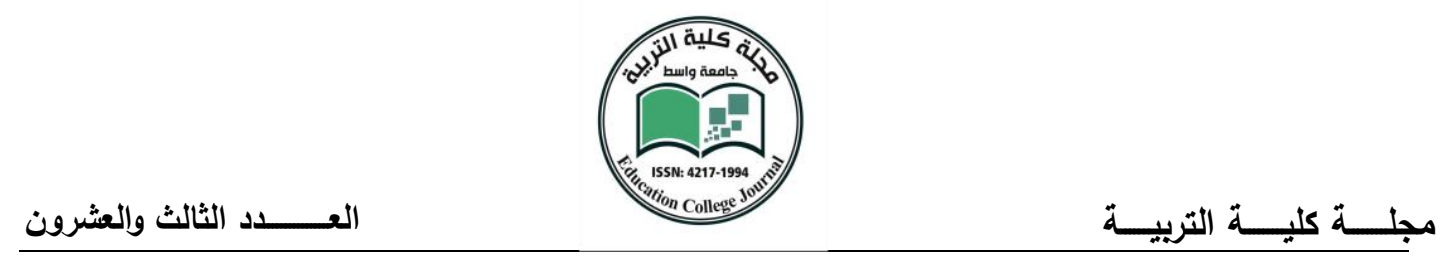

جدول (†)

يبين معنوية الفروق بين الاختبارات البعدية لمجموعتي البحث

\begin{tabular}{|c|c|c|c|c|c|c|c|c|}
\hline \multirow[t]{2}{*}{ د دلالة } & \multirow{2}{*}{ قالمتسبة T } & \multicolumn{2}{|c|}{ التجريبية } & \multicolumn{2}{|c|}{ الضابطة } & \multirow[t]{2}{*}{ وحدة القياس } & \multirow{2}{*}{ المتغيرات } & \multirow[t]{2}{*}{$ت$} \\
\hline & & $\varepsilon \pm$ & 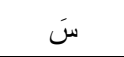 & $\varepsilon \pm$ & 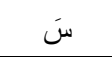 & & & \\
\hline معنوي & $\{.10$ & 1.04 & r.v & r.IT & $\varepsilon . .1$ & 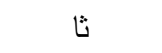 & السرعة الانتقالية & 1 \\
\hline معنوي & T.TY & 9.71 & $\uparrow \wedge . \leqslant 0$ & r.乏^ & $70 . V \leq$ & متر/ثانية & اختبار الخطوة لمدة & r \\
\hline منوي & $7.7 \leqslant$ & T.AT & YT.OA & r.Al & $r . . r \leq$ & متر/دقيقة & $\begin{array}{c}\text { الأكسجينية مؤشر القابلية } \\
\text { Vo2Max } \\
\text { النسبية }\end{array}$ & r \\
\hline معنوي & $V . . \varepsilon$ & IV.AT & $\wedge \leq 7.71$ & IV.r人 & 1.0 .01 & سمץ & حجم القلب المطلق & $\varepsilon$ \\
\hline معنوي & $\Lambda .7 \wedge$ & 1.10 & $10.7 r$ & r..rt & $1 T . \wedge \varepsilon$ & سم r/كغم & حجم القلب النسبي & o \\
\hline معنوي & Q.r & A & $7.97 \leq .0$ & $7 \leq .9 T$ & $01 \leqslant \varepsilon . V$ & مللتر/بالدقيقة & الناتج القلبي & 7 \\
\hline
\end{tabular}

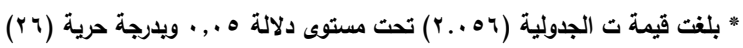

צ - r مناقشة نتائج البحث :

يتضح لنا من خلال عرض النتائج القبلية والبعدية للمجموعة التجربيية وتحليلها إن هناك فروقاً ذوات دلالة معنوية في الاختبارات كافة المعتمدة ولصالح الاختبارات البعدية ويعزو الباحثان ذلك كون تمرينات البدنية قد تضمنت الأسس العلمية لمكونات الحمل التدريبي والمنسجم مع تدريب هذه الصفات البدنية التي هي أساس في تطوير أنظمة إنتاج الطاقة للاعبين مما أدى إلى ظهور هذه المعنوية وهذا ما يؤكده محمد عثمان على ((إن البرنامج التذريبي الذي يراعي فيه مكونات الحمل المستخدم ومدى مناسبته للهدف الموضوع من أجله البرنامج ، واستخدام الحمل التدريب المقن والمبني على أسس علمية والذي يتتاسب مع كفاءة اللاعبين وإمكانياتهم يؤدي إلى الارتقاء بالمستوى الرباضي )). '" 
العـــــد الثالث والعثرون

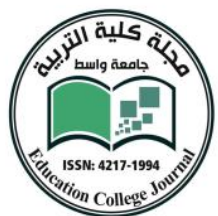

فضلا عن إن التمرينات البدنية وفق أنظمة إنتاج الطاقة التي يحتويها المنهج التنريبي والمنسجمة مع الحمل التدريبي للمتطلبات البدنية والمهارية للعبة كان أثرها واضح وكبير في تطوير هذه القدرات وبالتالي أنظمة إنتاج الطاقة وهذا ما يؤكده ماجد علي موسى (( تكون التمرينات الخاصة أكثر توجه ودقة من التمرينات العامة باعتبارها تساعد على تطوير القابلية الجسمية الخاصة ، وبالتالي ترفع من كفاءة الجسم وأجهزته المختلفة من خلال الجهد الواقع عليها جراء الأداء بالثدة القصوى والأقل من القصوى وحسب طبيعة التخصص المعني لذا يختلف حمل التمرينات الخاصة في دائرة التدريب )) . ب'

ويتضح من الجدول (V) إن هناك فروقا ذوات دلالة إحصائية بين الاختبارات البعدية للجموعتين البحث ظهر لنا إن هناك فروقا معنوية ولصالح المجموعة التجريبية في الاختبارات كافة المعتمدة ويعزو الباحثان الى إن التمرينات المستخدمة والمشابهة لأداء للاعبي كرة القدم من خلال الأداء السريع عن الققز التي تتميز به اللعبة التي تتطلب تغير المراكز والجري بسرعة من الدفاع للهجوم وبالعكس فضلا واللعب القوي ضد المنافس وطول زمن المنافسة وغيرها يجعل لابد من تطوير هذه القدرات الذي يراكبها ويلازمها تطوير في أنظمة إنتاج الطاقة لنجاح وتقدم المستوى للاعبين وهذا ما يؤكده قاسم حسن وجميل منصور (( إن الألعاب المنظمة ككرة القدم يركض اللاعب ما مجموعه بضع كيلومترات يتعرض خلالها إلى مختلف الظروف ومنها ظروف راكض المسافات القصيرة والطويلة والقز والسرعة مما بنطلب قوة كبيرة لأدائها فان تدريبه ينبغي أن يكون جيدا ويشمل كل الحالات الدذكورة () . آس

وفضلا عن أن التمرينات المستخدمة كان لها الدور الايجابي في تتمية القدرات البد نية للاعبين وتطويرها من خلال التتوع بالتدريبات المستخدمة لاكتساب اللاعبين بعض القدرات البدنية كالتحمل والسرعة والقوة الذي يساعد اللاعبين على إنتاج الطاقة وزيادتها تبعا للنظام المستخدم لكل قدرة بدنية التي تأني هذه التدريبات بمقدمة نأثيراتها على الجسم اللاعب بحيث ساعدت على تحسين القدرة الوظيفية لأنظمة إنتاج الطاقة فضلا عن الأداء والمستوى ألبدني للاعبين وهذا ما يتفق مع أمر اله احمد (( إن تدريب التحمل 
العـــــدد الثالث وإلعشرون

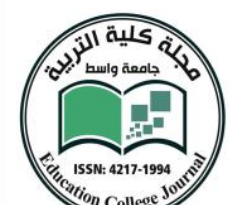

والسرعة والقوة والرشاقة في كرة القدم بأثكال تدريبية مختلفة بساعد على تحسين أنظمة الطاقة للاعبين

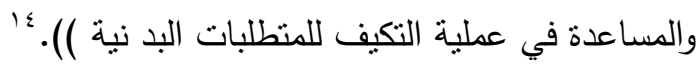

النبض عند الراحة اقل يدلل على ايجابية التمرينات المستخدمة مما ادى الى التحسن في العمل الوظيفي للقب لللك نجد ان مجموعة التجريبية اذ احدثت التمرينات عدد من المتغيرات ادت الى تحسين في كفاءة الوظيفية للجهازين الدوري والتتفسي مما انعكس الى العمل الفسيولوجي للقلب وهذا يتفق مع ما اكدنه سلدى من ان التغيرات التي تحدث في القلب نتيجة التنريب الرياضي منها الفسيولوجي التي وضعه اهمها انخفاض عدد ضربات القلب اثثاء الراحة نتيجة الجهد البدني وبخاصة تدريب المطاولة ويتفق هذا مع ما اكده (Roy) ((ان كميه العاليه للناتج القلبي والثغل الذي تقوم به عضلة القلب وجهاز الدوران والذي يرافقه انخفاض لمعدل ضربات القلب والذي يعكس تكيف الجهاز العصبي لعضلة القلب من جراء التراكمات التي أحدثثا الوحدات التدريبية في البرنامج التدريبي وحجمه وشدته التي هي كانت بصوره جيدة )).

وذلك تقبل الفرضيات البديلة التي اتبعها الباحثان في المتغيرات المبحوثة كافة لظهور الفروق الدالة إحصائيا بين الاختبارات القبلية والبعدية للمجموعتين التجريبية والضابطة ولصالح البعدية ، وبين الاختبارات البعدية للمجموعتين البحث ولصالح التجريبية . 


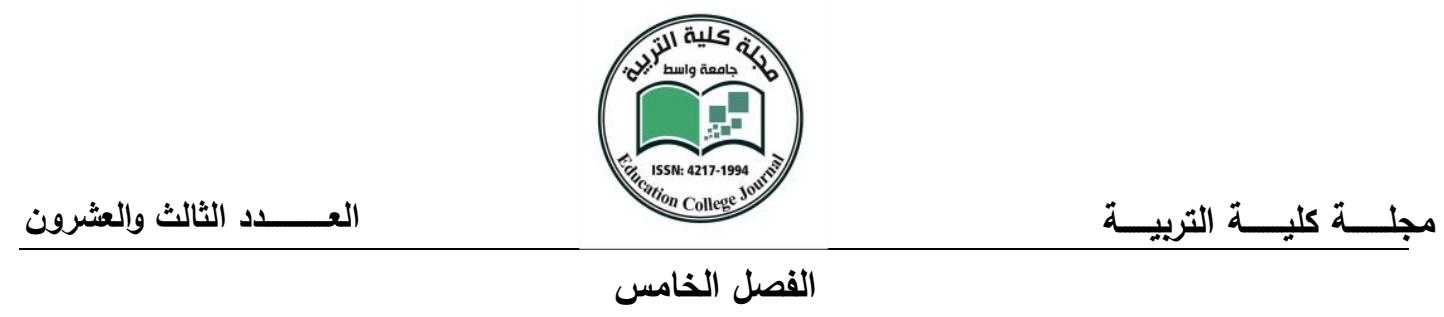

0 - الاستتتاجات والتوصيات

: - 0 - 1 الاستنتاجات

في ضوء المعالجات الاحصائية لنتائج اختبارات القدرات البدنية والوظيفية التي تم عرضها وتحليلها ومناقشتها توصلت الباحثة إلى الاستتناجات الآتية :

ا ـ وجود فروق معنوية بين نتائج الاختبارين القبلي والبعدي ولصالح الاختبار البعدي للمجموعتين الضابطة والتجريبية في نتائج اختبار القدرات البدنية واختبارات القدرات الوظيفية.

r. وجود فروق معنوية بين نتائج الاختبارات البعدية ولصالح المجموعة التجريبية في نتائج اختبار القدرات البدنية والوظيفية ، مما يدل على تأثثر التمرينات التدريبية التي طبقت في تطوير القدرات البدنية والوظيفية

". حققت المجموعة التجريبية تقدماً ملحوظاً في قدرات الهوائي واللاهوائي نتيجة لتطبيق تمرينات لتتمية القدرات البدنية مما أدي ذللك الى تظور ملحوظ في المؤثرات الوظيفية قيد البحث .

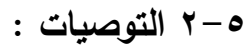

ا ـ الاهتمام بتتمية القدرات اللاهوائي والهوائية ضمن الوحدات التدربيية بصورة أكبر لما لها من تأثنير إيجابي علي تحسين القدرات البدنية والمؤشرات الوظيفي •

r. التأكيد على اعتماد المتغرات البيوكيميائية لدى اللاعبين عند تقنين الأحمال التدريبية. r. إجراء منل هذه الدراسة علي فعاليات أخرى بمراحل سنية مختلفة. Oाi 


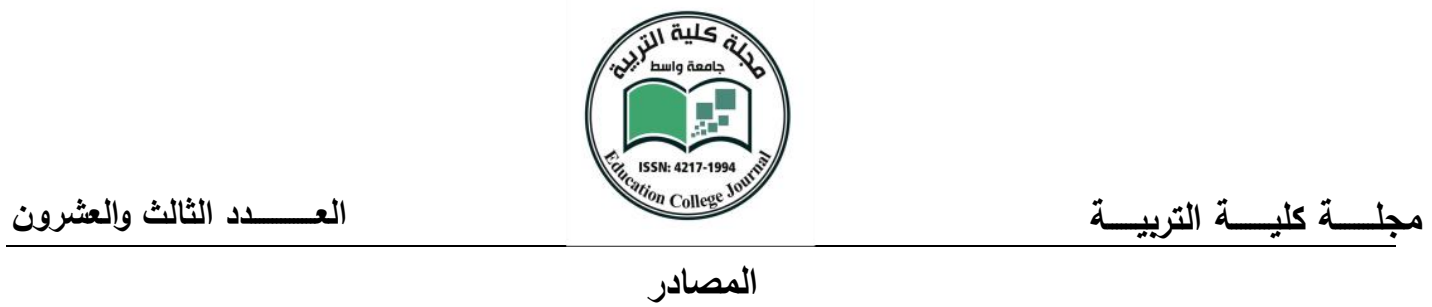

أبو العلا احمد ، احمد نصر الدين رضوان : فسبولوجيا اللباقة البدنية ، ط، ا، القاهرة : دار الفكر العربي • ابو العلا احمد عبد الفتاح ؛ حمل التدريب وصحة الرياضي ، القاهرة ، دار الفكر العربي ، 199 ـ ـ إيمان نجم الدين عباس ، منهج تدريبي مقترح لنطوير القدرة اللاهوائية والهوائية وتأثنرها في بعض المتغيرات البدنية والوظيفية والمهارية لدى لاعبي الريشة الطائرة ، أطروحة دكتوراه ، كلية التربية الرياضية للبنات - جامعة بغداد ، . r..o

بهاء الدين إبراهيم سلامة. التمثيل الحيوي للطاقة في المجال الرياضي ، القاهرة، دار الفكر العربي، 1999 ـ . عادل عبد البصبر علي ، التدريب الرياضي والتكامل بين النظرية والنطبيق ، القاهرة ، مركز الكتاب للنشر ، 1999 عبد المعطي عليان وآخرون ، التطورات المنهجية وعملية البحث العلمى ، عمان ، دار وائل للنشر ، ؟ ... . . ماجد علي موسى : التدريب الرياضى الحديث ـ البصرة ـ مطبعة النخيل ، 9 . . r. محمد جاسم الياسري ومروان عبد المجيد : الأساليب الإحصائية في مجالات البحوث التربوية ، طا ، ، عمان ،

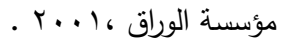
9. محمد حسن بسيوني ، تأثير تطوير القدرات الهوائية واللاهوائية علي بعض المتغيرات البيوكيميائية والفسيولوجية والمستوي الرقمي لمتسابقي المسافات المتوسطة ، المجلة العلمية للبحوث والدراسات فى التربية الرياضية ، العدد الرابع ، يناير ، كلية التربية الرياضية ببورسعيد ، جامعة قناة السويس ، ج . . r. • 1. محمد نصر الدين رضوان ؛ طرق قياس الجهد البدنى في الرياضة ، القاهرة ، مركز الكتاب للنشر ، 1991.

1 ا.مصطفى حسين باهي، المعاملات العلمية بين النظرية والنطبيق ، القاهرة ، مركز الكتاب للنشر،999 199. ז ا.وجيه محجوب (وآخرون ) : طرق البحث العلمى ومناهجه في التربية الرياضية ، بغداد ، مطبعة التعليم العالي والبحث العلمي ، 1911 .

- Mudhafar A. SH. "Mechanical Activity of the heart \& Sinus Arrhythmia In evaluation of Physical Working Capacity in Athletes" (Ph.D. Thesis, Ministry of Health, Moscow1979) P. 57.

- Roy-J-Shephard,:Responses of the cardio rascular system to exercise and training. Current the rapy in sports medicinge. Toronte.can ada. 1995. 


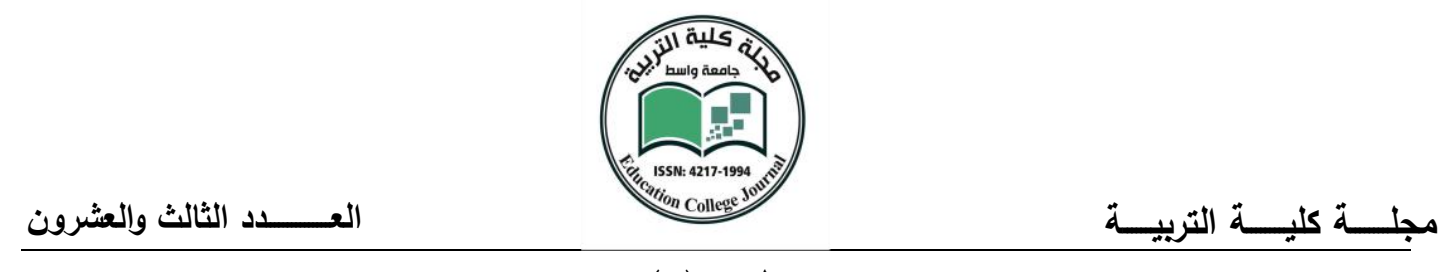

ملحق (1)

الوحدة التدريبية : الأولى

الأسبوع : الأول

طريقة التدريب : فتري مرتفع الثدة

\begin{tabular}{|c|c|c|c|c|c|c|c|}
\hline الملاحظات & المجاميع بين & المجاميع & التكرار & التكرار & الشدة & الإجراءات & اليوم \\
\hline & r-rد & $r$ & $v: 1$ & 0 & $\% 90$ & 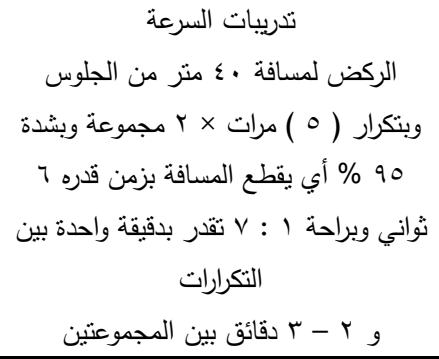 & \\
\hline & Y-rد & r & $7: 1$ & - & $\% q$. & 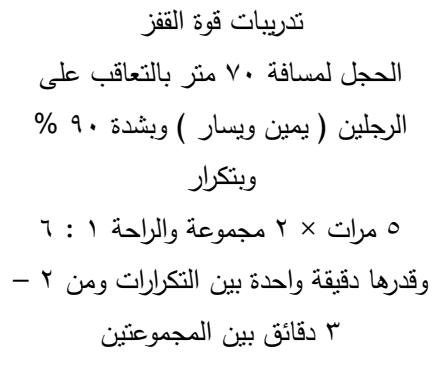 & \\
\hline & r-rد & r & $\leq: 1$ & 0 & $\% \wedge$. & 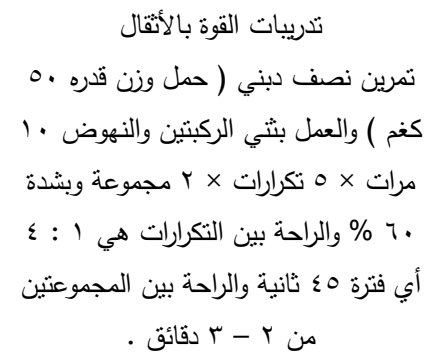 & \\
\hline
\end{tabular}




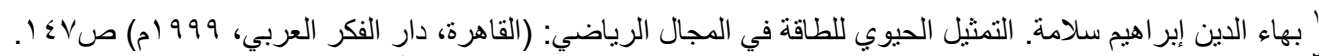

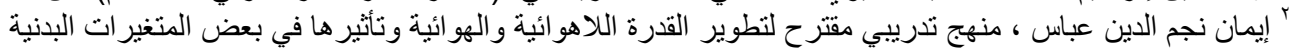

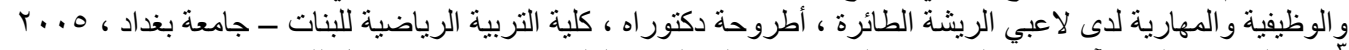

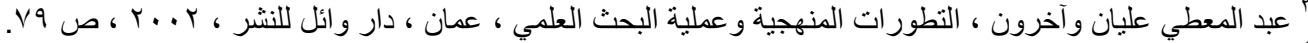

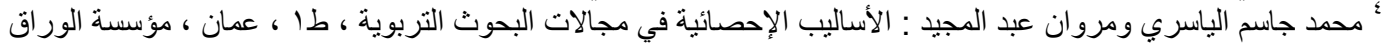

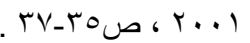

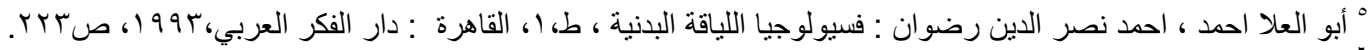

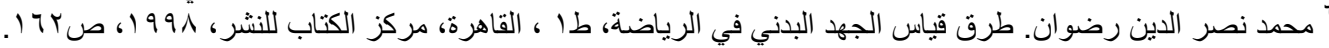
${ }^{7}$ Mudhafar A. SH. "Mechanical Activity of the heart \& Sinus Arrhythmia In evaluation of Physical Working Capacity in Athletes" (Ph.D. Thesis, Ministry of Health, Moscow-1979) P. 57.

^و وجيه محجوب (و آخرون ) : طرق البحث العلمي ومناهجه في التربية الرياضية ، بغداد ، مطبعة التعليم العالي و البحث

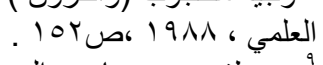

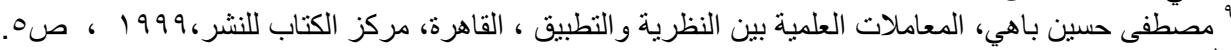

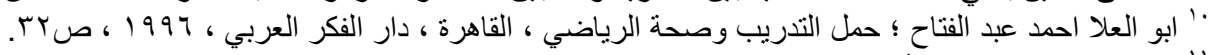

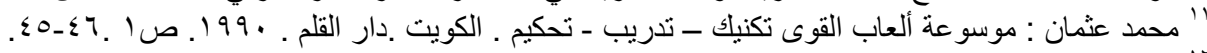

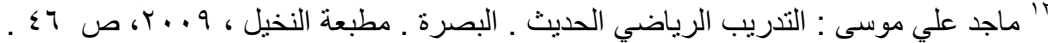

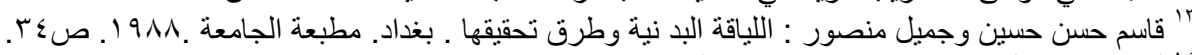

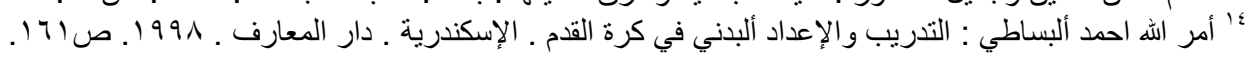
${ }^{15}$ Roy-J-Shephard,:Responses of the cardio rascular system to exercise and training. Current the rapy in sports medicinge. Toronte.can ada. 1995 